\title{
Acetone and Perdeuterated Acetone in UV-IMS
}

\begin{abstract}
Measuring a mixture of acetone and perdeuterated acetone (acetone-d6) with an ultra-high resolution drift time ion mobility spectrometer (resolving power of $\left.R_{p}=235\right)$ and ultraviolet ionization $(10.6 \mathrm{eV}$ ) at ambient pressure reveals three separated peaks. Two of the peaks can easily be associated with acetone and perdeuterated acetone. In a former publication several findings indicated an exchange of a methyl group and the formation of a $\mathrm{H}_{3} \mathrm{COCD}_{3}$ related peak. In this work the formed ion species were analyzed with a high resolution drift time ion mobility time of flight mass spectrometer. The mass spectra clearly show the formation of three proton-bound dimer peaks whereas the peak between acetone and acetone-d6 is a proton-bound mixed dimer consisting of one acetone and one acetone-d6 molecule.
\end{abstract}

\section{Introduction}

The separation of ions in drift time ion mobility spectrometers (IMS) is based on the collision of the ions with neutral drift gas under the influence of an electric field [1]. Since IMS are often operated at ambient pressure (without the need of bulky vacuum pumps), and have extremely low limits of detection (low $\mathrm{ppb}_{\mathrm{V}}$ and even $\mathrm{ppt}_{\mathrm{V}}$ in less than a second) when operated with atmospheric pressure chemical ionization (APCI) sources [2-5], they are widely used in several applications. Besides the academic value of ultra-high resolution IMS, e.g. for investigating ion formation processes, ultra-high resolution is required in applications where preseparation is too time-demanding, e.g. in most security applications [6-9], but target compounds and interferents have similar ion mobilities or target compound peaks are masked by the reactant ion peak. Furthermore, increasing resolution helps improving SNR and thus detection limits [10]. Besides APCI, photoionization sources at atmospheric pressure (APPI) are also used in IMS for substances difficult to ionize by APCI, or to reduce chemical cross sensitivities possible in APCI [11-18].

The ion mobility $K$ can be theoretically estimated from the ions' structure and mass [19-21] or be calculated from experimental IMS measurements. Therefore, $K$ is defined as follows:

$$
K=\frac{L}{E \cdot t_{D}}
$$

Whereas $L$ is the length of the drift region, $E$ the electric field in the drift region and $t_{D}$ the drift time of the ions needed to pass the drift region. Usually, this value is normalized to a temperature $T_{0}=273.15 \mathrm{~K}$ and a pressure $p_{0}=1013.25 \mathrm{hPa}$. The so called reduced mobility $K_{0}=K \cdot \frac{p}{p_{0}} \cdot \frac{T_{0}}{T}$ is expected to be nearly independent of the ambient conditions and instrumental design. [1] It can be used to roughly compare peaks between different IMS instruments. However, this approach does for example not take into account the drift and sample gas composition (e.g. water content), the electrical field strengths in the drift region, and further temperature effects, all affecting the ion mobility. Thus, several $K_{0}$ values for acetone can be found in literature. For example, Vautz et al. [17] reported a value of $K_{0}=1.84 \mathrm{~cm}^{2} \mathrm{~V}^{-1} \mathrm{~s}^{-1}$, whereas Xie et al. [16] published a value of $K_{0}=1.74 \mathrm{~cm}^{2} \mathrm{~V}^{-1} \mathrm{~s}^{-1}$ both for acetone ions in nitrogen ionized with a $10.6 \mathrm{eV}$ photo ionization source. Xie et al. assigned the peak to a protonated acetone monomer, whereas Vautz et al. only stated the mobility according to the peak position without further clarification of the ion species. 

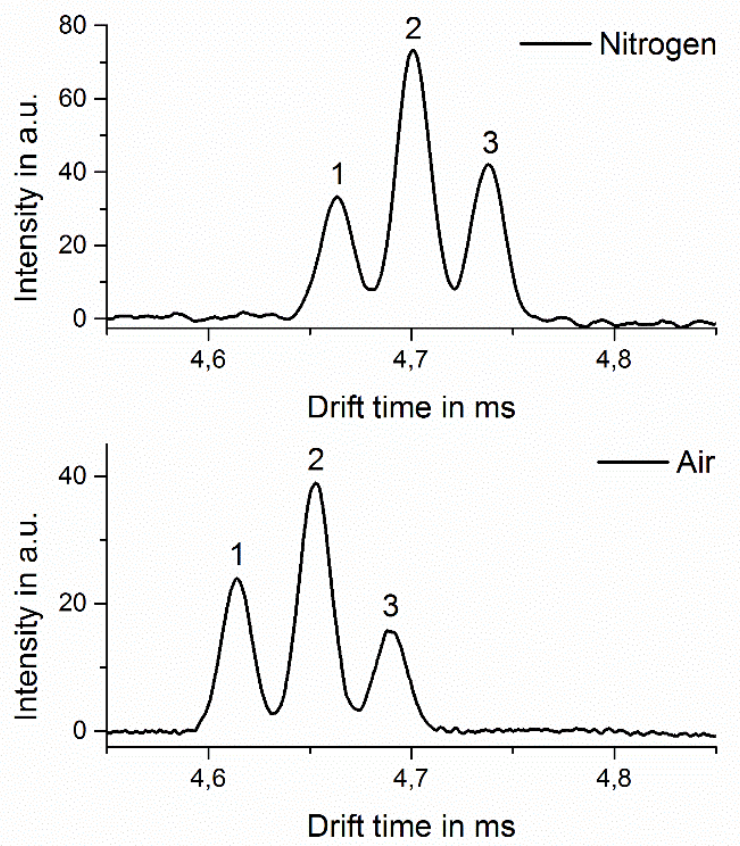

Figure 1. Ultra-high-resolution ion mobility spectrum (resolving power of $\mathrm{R}_{\mathrm{p}}=235$ ) of an acetone/acetone-d6 mixture in nitrogen (top) and air (bottom). As presented in this work the peaks correspond to a proton-bound acetone dimer (1), $K_{0}$ of $1.85 \mathrm{~cm}^{2} V^{-1} \mathrm{~s}^{-1}$ in nitrogen, $K_{0}$ of $1.87 \mathrm{~cm}^{2} V^{-1} \mathrm{~s}^{-1}$ in air, a proton-bound mixed acetone dimer (2), $K_{0}$ of $1.83 \mathrm{~cm}^{2} \mathrm{~V}^{-1} \mathrm{~s}^{-1}$ in nitrogen, $K_{0}$ of $1.85 \mathrm{~cm}^{2} \mathrm{~V}^{-1} \mathrm{~s}^{-1}$ in air and a proton-bound acetone-d6 dimer (3), $K_{0}$ of $1.82 \mathrm{~cm}^{2} V^{-1} \mathrm{~s}^{-1}$ in nitrogen, $K_{0}$ of $1.84 \mathrm{~cm}^{2} \mathrm{~V}^{-1} \mathrm{~s}^{-1}$ in air (from left to right). Adapted from Kirk et al. [22]

In Figure 1 (top), an ultra-high resolution ion mobility spectrum (10.6 eV photo ionization source) of a mixture of acetone and acetone-d6 in nitrogen is shown, as it was observed in a former publication [22] but not further investigated. The peak number 1 in Figure 1 corresponds to acetone and has a $K_{0}$ of $1.85 \mathrm{~cm}^{2} \mathrm{~V}^{-1} \mathrm{~s}^{-1}$ in nitrogen. So this $K_{0}$ corresponds with those mentioned above. The peak number 3 corresponds to acetone-d6 and has a $K_{0}$ of $1.82 \mathrm{~cm}^{2} V^{-1} \mathrm{~s}^{-1}$ in nitrogen. In Table 1 the $K_{0}$ values of the peaks in Figure 1 are summarized. Due to the applied APPI a direct ionization of the analyte molecule $M$, as shown in eq. 2, is expected. [23]

$$
M+h v \rightarrow M^{++}
$$

However, these radical cations further react, likely according to one of the reactions shown in eqs. 3 and 4 [24] suggested by literature. Thus, one possibility for the formation of $\mathrm{MH}^{+}$is the proton abstraction from another analyte molecule, another possibility is the proton abstraction from a solvent $S$ present in the reaction region, e.g. water. [25]

$$
\begin{aligned}
& M^{{ }^{+}}+M \rightarrow M H^{+}+[M-H] \\
& M^{++}+S \rightarrow M H^{+}+[S-H]
\end{aligned}
$$

However, Klee et al. [26] showed evidence for a more complex generation of protonated analyte molecules. Instead of a direct interaction between the molecule $M$ and the radical cation, a cluster formation with background water occours. Due to fast intracluster reactions, proton-bound water clusters are generated which then can lead to the protonated analyte ion. 
Table 1. $K_{0}$ values of the measured peaks

$\begin{array}{ccccc}\text { Peak number } & \text { species } & \mathrm{m} / \mathrm{z} & \begin{array}{c}K_{0}, \text { nitrogen in } \\ \mathrm{cm}^{2} V^{-1} s^{-1}\end{array} & \begin{array}{c}K_{0}, \text { air in } \\ \mathrm{cm}^{2} V^{-1} \mathrm{~s}^{-1}\end{array} \\ 1 & \begin{array}{c}\text { proton-bound } \\ \text { acetone dimer } \\ \text { proton-bound } \\ \text { mixed acetone } \\ \text { dimer }\end{array} & 117 & 1.85 & 1.87 \\ 3 & \begin{array}{c}\text { proton-bound } \\ \text { acetone-d6 dimer }\end{array} & 123 & 1.83 & 1.84\end{array}$

The $K_{0}$ value of the acetone peak is in the range of the $K_{0}$ value of the proton-bound acetone dimer in air when using a $\beta$-radiation source. Vautz et al. [17] report a $K_{0}$ of $1.83 \mathrm{~cm}^{2} V^{-1} \mathrm{~s}^{-1}$ and the calculated $K_{0}$ of the acetone dimer presented by Kirk et al. [27] is $1.87 \mathrm{~cm}^{2} \mathrm{~V}^{-1} \mathrm{~s}^{-1}$. Watts [28] published values of $K_{0}=2.01 \mathrm{~cm}^{2} \mathrm{~V}^{-1} \mathrm{~s}^{-1}$ and $K_{0}=1.85 \mathrm{~cm}^{2} \mathrm{~V}^{-1} \mathrm{~s}^{-1}$ for the acetone monomer and dimer, respectively. In Figure 1 a spectrum of the mixture in nitrogen as well as a spectrum of the mixture in air is shown. A comparison of both indicates that the ionization is the same in air and nitrogen. As expected, the ion species have a slightly higher mobility in air. Here, the $K_{0}$ of the acetone related peak is $1.87 \mathrm{~cm}^{2} \mathrm{~V}^{-1} \mathrm{~s}^{-1}$, which matches the reported values for air.

\section{Experimental}

The ultra-high-resolution IMS measurements in this work were conducted with a system described elsewhere [22; 27; 29]. Operational parameters are given in Table 2.

Table 2. Operational parameters of the IMS setup

$\begin{array}{ccc}\text { parameter } & \begin{array}{c}\text { ultra-high- } \\ \text { resolution setup }\end{array} & \begin{array}{c}\text { high-resolution } \\ \text { setup }\end{array} \\ \begin{array}{c}\text { drift length } \\ \text { drift region diame- } \\ \text { ter }\end{array} & 153 \mathrm{~mm} & 77 \mathrm{~mm} \\ \begin{array}{c}\text { UV source energy } \\ \text { injection voltage }\end{array} & 10.6 \mathrm{eV} & 21 \mathrm{~mm} \\ \text { repetition rate } & 1800 \mathrm{~V} & 10.6 \mathrm{eV} \\ \text { drift voltage } & 44 \mathrm{~Hz} & 500 \mathrm{~V} \\ \text { drift gas flow } & 25 \mathrm{kV} & 40 \mathrm{~Hz} \\ \text { sample gas flow } & 150 \mathrm{mLs} / \mathrm{min}^{1} & 150 \mathrm{mLs} / \mathrm{min}^{1} \\ \text { dew point of drift } \\ \text { and sample gas } \\ \text { operating pressure }\end{array}$

For analyzing the ion masses, a mass spectrometer (micrOTOF II, Bruker) coupled with our high-resolution IMS (resolving power of $R_{p}=75$ ) was used. The experimental setup is basically an enhanced version of the IMS-MS described by Heptner et al. [30]. The IMS tube is now directly positioned in front of the inlet capillary of the MS. The Faraday detector plate is replaced by a Faraday detector grid, which is shielded by two aperture grids. Basically the transmission of ions in the MS is controlled by adjusting the potentials of the second aperture grid and the inlet capillary. One major benefit of this setup is higher ion transmission into MS. With this modified detector it is now possible to measure the ion mobility spectrum and to simultaneously guide a certain portion (time resolved window function) or all ions to the capillary interface of the micrOTOF II mass spectrometer. A more detailed description and characterization of our improved IMS-MS will be published elsewhere. In both devices, IMS-MS and ultra-high resolution IMS, analytes were ionized with a krypton photoionization lamp from Heraeus (10.6 eV). Due to unknown mass discrimina-

${ }^{1} \mathrm{mLs} / \mathrm{min}$ : milliliter standard per minute, mass flow at reference conditions $20^{\circ} \mathrm{C}$ and $1013 \mathrm{mbar}$ 
tion effects in the MS interface, quantitative MS measurements are not possible at this time. The drift gas in the IMS-MS system is purified dry air.

All chemicals were obtained from Merk (former Sigma Aldrich) with a purity of $99 \%$ and are used without further purification. To generate a constant analyte concentration, a permeation oven (VICI Dynacal 150), set to $35{ }^{\circ} \mathrm{C}$, with a homemade permeation tube was used. The oven is continuously purged with $600 \mathrm{mLs} / \mathrm{min}$ of purified air or nitrogen. An adjustable portion of the gas is diluted with dried air or nitrogen to achieve the desired analyte concentration in the sample gas.

Two moisture traps (SUPELCO Big Moisture Trap and SUPELCO Molecular Sieve 5A Moisture Trap) in series are used to purify and dry the air and nitrogen to a dew point of $-90^{\circ} \mathrm{C}$. As the instrument is connected with PTFE gas supply lines the dew point at the instrument is $-70{ }^{\circ} \mathrm{C}$.

\section{Results and discussion}

As shown in Figure 1, ultra-high resolution UV-IMS reveals three separated peaks when analyzing the mixture of acetone and acetone-d6 in nitrogen. For identification of the related ion species, a high resolution ion mobility spectrometer $\left(R_{p}=75\right)$ was coupled to a micrOTOF II mass spectrometer. The ion mobility spectra of acetone, acetone-d6 and a mixture of both compounds in air are shown in Figure 2. Due to its lower resolving power, the IMS used in the IMS-MS setup cannot resolve the three peaks visible at ultra-high resolution. Unfortunately, constructive and electrical constraints did not allow the ultra-high resolution IMS to be coupled to the micrOTOF II mass spectrometer.

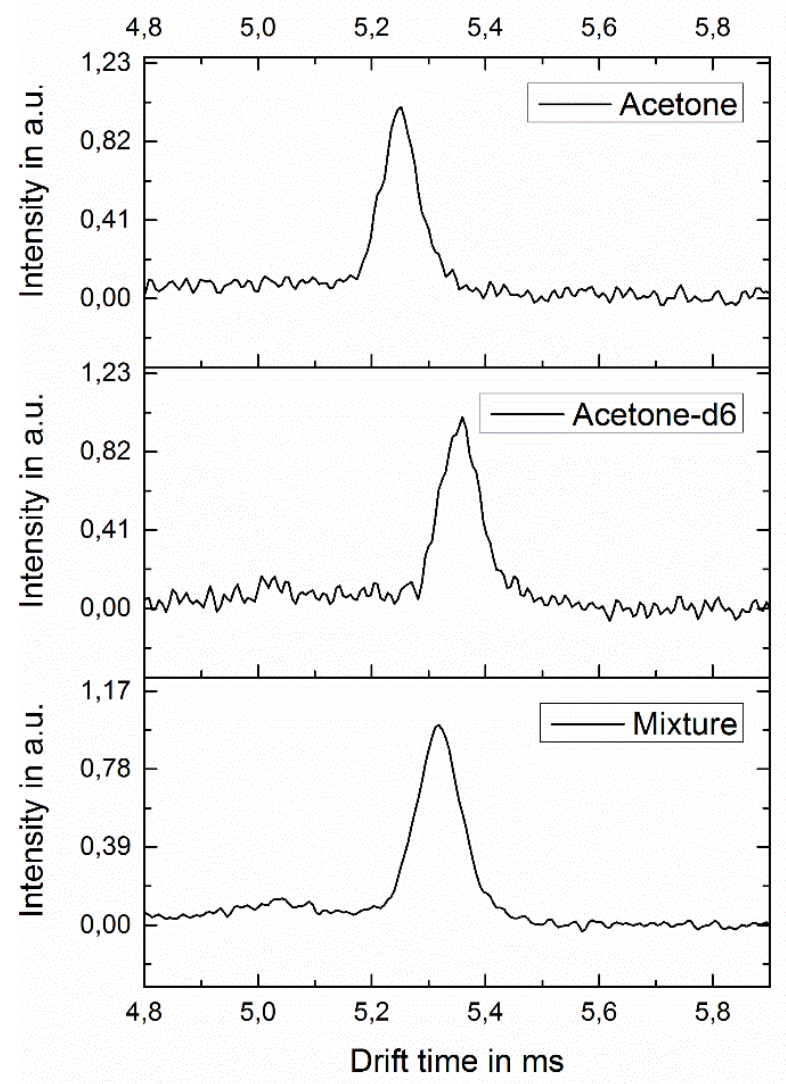

Figure 2. High resolution IMS spectra of acetone, acetone-d6 and a mixture of both substances in air.

In Figure 3, mass spectra of acetone (top), acetone-d6 (middle) and the mixture of both substances (bottom) in air are shown. Hereinafter the main peaks of the spectra are discussed. Measuring acetone in air, the mass-to-charge ratios ( $\mathrm{m} / \mathrm{z}$ ) of the protonated acetone monomer $(\mathrm{m} / \mathrm{z}=59)$ and the proton-bound acetone dimer $(\mathrm{m} / \mathrm{z}=117)$ are observed. With UV ionization, initially a direct ionization would be expected. However, in for acetone reactions with neutral acetone or water can lead to protonated acetone monomers and dimers as mentioned above and described in several publications. [24; 25; 31] Due to the acetone concentration of $500 \mathrm{ppb}$ required for sufficient peak height in UV-IMS, only proton-bound acetone dimers are present in the ion mobility spectrum (one single peak with $K_{0}$ of proton-bound acetone dimers). In the IMS-MS most of the protonated acetone dimers fragment and protonated acetone monomers become visible in the mass spectrum. Beside $\mathrm{m} / \mathrm{z}=59$ (protonated acetone monomers) and $\mathrm{m} / \mathrm{z}=$ 117 (proton-bound acetone dimers), a mass-to-charge ratio of $\mathrm{m} / \mathrm{z}=101$ can be detected. Since a krypton photoionization lamp with a $10.6 \mathrm{eV}$ energy band is used, a fragment $\left(\mathrm{CH}_{3} \mathrm{CO}^{+}\right)$with $\mathrm{m} / \mathrm{z}=43$ could be formed. The $\mathrm{m} / \mathrm{z}=101$ could be explained by the formation of an adduct of this fragment and a neutral acetone molecule [32]. Another more likely explanation is a water cluster $\left(\left(\mathrm{H}_{2} \mathrm{O}\right)_{4} \mathrm{~N}_{2} \mathrm{H}^{+}\right)$[33; 28]. This is also supported by the fact that the $\mathrm{m} / \mathrm{z}$ of 101 is present in all mass spectra shown in Figure 3. An 
analogous situation is obtained for acetone-d6 (Figure 3 middle) with a concentration of $500 \mathrm{ppb}_{\mathrm{v}}$. The $\mathrm{m} / \mathrm{z}$ of the protonated acetone-d6 monomer is 65 resulting in an $\mathrm{m} / \mathrm{z}$ of 129 for the proton-bound acetone-d6 dimer. Such ion species have also been measured by Santos et al. [34] with an ESI-MS, so this reaction does not only occur with UV ionization. As mentioned above the protonation of acetone is expected via a reaction with water or neutral acetone. However, for acetone-d6 no m/z of 66 and the m/z of 130 could be observed, which would correspond to a deuterated acetone-d6 and a deuterated acetone-d6 dimer with deuteriums from deuterated neutrals. This would lead to the reaction mechanism proposed in eq. 4, with the proton stemming from a neutral solvent such as water and not from the analyte as in eq. 3. However, the water cluster reactions proposed by Klee et al. [26] would be also possible. In this case, the proton that protonates the acetone ion is not necessarily the same that was protonating the reacting water cluster, since Klee et al. showed that the water clusters are protonated by a proton from the analyte. This would be a deuterium in our case and therefore cannot not lead to the observed mass spectrum. Similar observations are also reported by other groups using different perdeuterated substances as toluene-d8 [26] and anisole-d8 [35]. Additionally, an ion species with $\mathrm{m} / \mathrm{z}=106$ is formed but we do not have a sound explanation yet. Figure 3 (bottom) shows a mass spectrum of the acetone/acetone-d6 mixture (500 ppbv each) in air. In addition to the $\mathrm{m} / \mathrm{z}$ values of the pure substances, the mixture yields an additional $\mathrm{m} / \mathrm{z}$ of 123 . This corresponds to a proton-bound mixed dimer of acetone and acetone-d6. The formation of mixed dimers is known and was described by Ewing et al. [36]. Therefore, the peaks in Figure 1 are proton-bound acetone dimers, proton-bound acetone/acetone-d6 mixed dimers and proton-bound acetone-d6 dimers.

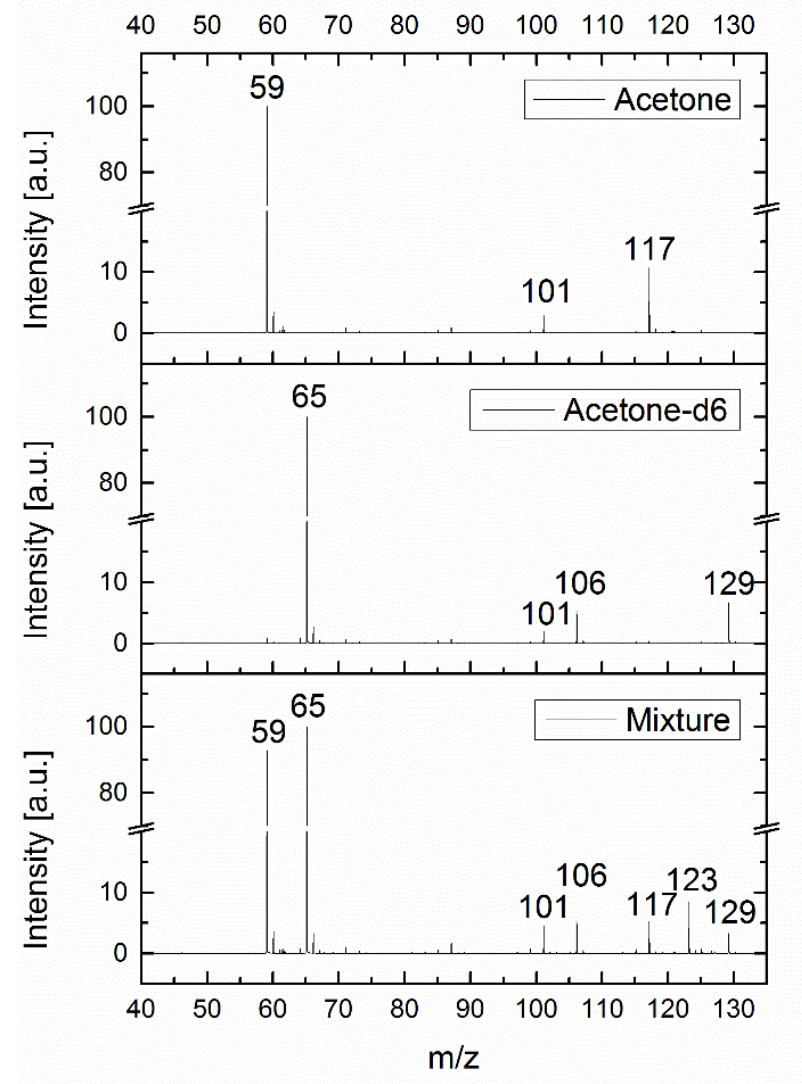

Figure 3. Mass spectra of acetone, acetone-d6 and a mixture of both in air. The numbers indicate the m/z of the main peaks.

\section{Conclusion}

In this work, it is shown that under the stated conditions, the peaks of a mixture of acetone and acetone-d6 in an ultra-high resolution IMS with UV ionization are proton-bound dimers of acetone and acetone-d6 as well as a proton-bound mixed dimer of both species. The proton originates predominantly from the water present in the reaction region. No monomer ions of acetone or acetone-d6 can be detected with the UV-IMS.

\section{REFERENCES}

\section{Eiceman GA, Karpas Z (1994) Ion mobility spectrometry. CRC Press, Boca Raton}

2. Armenta S, Alcala M, Blanco M (2011) A review of recent, unconventional applications of ion mobility spectrometry (IMS). Analytica chimica acta 703:114-123 
3. Kuklya A, Reinecke T, Uteschil F, Kerpen K, Zimmermann S, Telgheder U (2017) X-ray ionization differential ion mobility spectrometry. Talanta 162:159-166

4. Crawford CL, Hill HH (2013) Comparison of reactant and analyte ions for ${ }^{6}{ }^{3} \mathrm{Nickel}$, corona discharge, and secondary electrospray ionization sources with ion mobility-mass spectrometry. Talanta 107:225-232

5. Baether W, Zimmermann S, Gunzer F (2012) Pulsed electron beams in ion mobility spectrometry. Reviews in Analytical Chemistry 31:

6. Puton J, Namieśnik J (2016) Ion mobility spectrometry. TrAC, Trends Anal. Chem. 85:10-20

7. Eiceman GA (2002) Ion-mobility spectrometry as a fast monitor of chemical composition. TrAC, Trends Anal. Chem. 21:259-275

8. Hill HH, Simpson G (1997) Capabilities and limitations of ion mobility spectrometry for field screening applications. Field Analyt. Chem. Technol. 1:119-134

9. Eiceman GA, Stone JA (2004) Peer Reviewed: Ion Mobility Spectrometers in National Defense. Anal. Chem. 76:390A397A

10. Kirk AT, Zimmermann S (2015) An analytical model for the optimum drift voltage of drift tube ion mobility spectrometers with respect to resolving power and detection limits. Int. J. Ion Mobil. Spec. 18:129-135

11. Baim MA, Eatherton RL, Hill HH (1983) Ion mobility detector for gas chromatography with a direct photoionization source. Anal. Chem. 55:1761-1766

12. Leasure CS, Fleischer ME, Anderson GK, Eiceman GA (1986) Photoionization in air with ion mobility spectrometry using a hydrogen discharge lamp. 58:2142-2147

13. Eiceman GA, Vandiver VJ (1986) Charge-exchange in binary mixtures of polycyclic aromatic hydrocarbons using photoionization-ion mobility spectrometry. Anal. Chem. 58:2331-2335

14. Sielemann S, Baumbach JI, Schmidt H, Pilzecker P (2000) Quantitative analysis of benzene, toluene, and m-xylene with the use of a UV-ion mobility spectrometer. Field Analyt. Chem. Technol. 4:157-169

15. St. Sielemann, Baumbach JI, Schmidt H, Pilzecker P (2001) Detection of alcohols using UV-ion mobility spetrometers. Analytica chimica acta 431:293-301

16. Xie Z, Sielemann S, Schmidt H, Li F, Baumbach JI (2002) Determination of acetone, 2-butanone, diethyl ketone and BTX using HSCC-UV-IMS. Anal. Bioanal. Chem. 372:606-610

17. Vautz W, Bödeker B, Baumbach JI, Bader S, Westhoff M, Perl T (2009) An implementable approach to obtain reproducible reduced ion mobility. Int. J. Ion Mobil. Spec. 12:47-57

18. Puton J, Holopainen SI, Mäkinen MA, Sillanpää, Mika E T (2012) Quantitative response of IMS detector for mixtures containing two active components. Anal. Chem. 84:9131-9138

19. Langevin MP (1905) Une formule fondamentale de théorie cinétique. Ann. Chim. Phys. 5:245-288

20. Mason EA, McDaniel EW (1988) Transport Properties of Ions in Gases. Wiley-VCH Verlag GmbH \& Co. KGaA, Weinheim, FRG

21. Siems WF, Viehland LA, Hill HH (2012) Improved momentum-transfer theory for ion mobility. 1. Derivation of the fundamental equation. Anal. Chem. 84:9782-9791

22. Kirk AT, Raddatz C-R, Zimmermann S (2017) Separation of Isotopologues in Ultra-High-Resolution Ion Mobility Spectrometry. Anal. Chem. 89:1509-1515

23. Kauppila TJ, Kersten H, Benter T (2014) The ionization mechanisms in direct and dopant-assisted atmospheric pressure photoionization and atmospheric pressure laser ionization. J. Am. Soc. Mass Spectrom. 25:1870-1881

24. Syage JA (2004) Mechanism of M + H+ formation in photoionization mass spectrometry. Journal of the American Society for Mass Spectrometry 15:1521-1533

25. Kamel A, Jeanville P, Colizza K, J-Rivera LE (2008) Mechanism of $\mathrm{m}+\mathrm{h}+$ formation in atmospheric pressure photoionization mass spectrometry: identification of propionitrile in acetonitrile with high mass accuracy measurement and tandem mass spectrometry and evidence for its involvement in the protonation phenomenon. Journal of the American Society for Mass Spectrometry 19:1579-1589

26. Klee S, Albrecht S, Derpmann V, Kersten H, Benter T (2013) Generation of ion-bound solvent clusters as reactant ions in dopant-assisted APPI and APLI. Anal. Bioanal. Chem. 405:6933-6951 
27. Kirk AT, Allers M, Cochems P, Langejuergen J, Zimmermann S (2013) A compact high resolution ion mobility spectrometer for fast trace gas analysis. Analyst 138:5200-5207

28. Peter Watts Use of Ion Mobility spectroscopy for the detection and analysis of Vapours. Anal. Proc. 1991:328-331

29. Kirk AT, Zimmermann S (2015) Pushing a compact $15 \mathrm{~cm}$ long ultra-high resolution drift tube ion mobility spectrometer with $\mathrm{R}=250$ to $\mathrm{R}=425$ using peak deconvolution. Int. J. Ion Mobil. Spec. 18:17-22

30. Heptner A, Reinecke T, Langejuergen J, Zimmermann S (2014) A gated atmospheric pressure drift tube ion mobility spectrometer-time-of-flight mass spectrometer. J. Chrom. A 1356:241-248

31. Sieck LW, Ausloos P (1972) Reactions of the acetone cation. Implications for the radiolysis of acetone. Radiation Research 52:47-58

32. Hunter JA, Johnson CAF, McGill IJM, Parker JE, Smith GP (1987) Some gas-phase ion-molecule reactions of acetone. J. Chem. Soc., Faraday Trans. 2 83:2025-2034

33. Spangler GE, Carrico JP (1983) Membrane inlet for ion mobility spectrometry (plasma chromatography). Int. J. Mass Spectrom. Ion Phys. 52:267-287

34. Santos LS, Catharino R, Eberlin MN (2005) The proton-bound dimer of acetone. Journal of mass spectrometry : JMS 40:127-128

35. Kauppila TJ, Kostiainen R, Bruins AP (2004) Anisole, a new dopant for atmospheric pressure photoionization mass spectrometry of low proton affinity, low ionization energy compounds. Rapid Commun. Mass Spectrom. 18:808-815

36. Ewing RG, Eiceman GA, Stone JA (1999) Proton-bound cluster ions in ion mobility spectrometry. Int. J. Mass Spectrom. 193:57-68 